\title{
Review of: "Factors influencing the injury severity score and the probability of survival in patients who fell from height"
}

\author{
Makoto $\mathrm{Aoki}^{1}$ \\ 1 Gunma University
}

Potential competing interests: The author(s) declared that no potential competing interests exist.

Thank you for giving me the opportunity to review the manuscript. This manuscript investigated the factors influencing the ISS and Ps in patients who fell from height. And the results demonstrated the fall height $\geq 5 \mathrm{~m}$, properties of the impact surface and body position at the time of surface impact. I agreed with the results of this study and the conclusion was supported by results. I have a few comments of this publication. \#1. The authors subclassified the patients with and without suicide attempts. This subgroup was important and I recommend the authors to evaluate whether there was an interaction or not. \#2. To solve the major limitation of shortage of mortality patients, the authors substitute for ISS and Ps. And these soft outcomes were thought to be nice idea, while, I thought the cutoff point of Ps $90 \%$ was OK? More strict Ps $50 \%$ could not be set? 